\title{
Do Sub-syndromal Manic Symptoms Influence Outcome in Treatment Resistant Depression in Adolescents? A Latent Class Analysis from the TORDIA study
}

Fadi T. Maalouf, M.D., Giovanna Porta, M.S., Benedetto Vitiello, M.D., Graham Emslie, M.D., Taryn Mayes, M.S., Gregory Clarke, Ph.D., Karen D. Wagner, M.D., Ph.D., Joan Rosenbaum Asarnow, Ph.D., Anthony Spirito, Ph.D., Martin Keller, M.D., Boris Birmaher, M.D., Neal Ryan, M.D., Wael Shamseddeen, M.D., M.P.H, Satish lyengar, Ph.D., and David A. Brent, M.D.

Dr. Maalouf is with the American University of Beirut; Drs. Maalouf, Ryan, lyengar, Birmaher and Brent and Ms. Porta are with the University of Pittsburgh; Dr. Vitiello is with the National Institute of Mental Health; Dr. Emslie and Ms. Mayes are with the University of Texas-Southwestern Medical Center; Dr. Clarke is with Kaiser Permanente Center for Health Research; Dr. Wagner is with University of Texas-Galveston; Dr. Asarnow is with University of California, Los Angeles; Drs. Spirito and Keller are with Brown University; Dr. Shamseddeen is with Rosalind Franklin University of Medicine and Sciences, North Chicago, IL.

\section{Abstract}

Background-To identify distinct depressive symptom trajectories in the TORDIA study and determine their correlates.

Methods-Latent Class Growth Analysis (LCGA) using the Children's Depression Rating Scale -Revised (CDRS-R) through 72 weeks from intake.

Results-3 classes were identified: (1) little change in symptomatic status ("NO"), comprising $24.9 \%$ of participants, with a 72 -week remission rate of $25.3 \%$; (2) slow, steady improvement ("SLOW"), comprising $47.9 \%$ of participants, with a remission rate of $60.0 \%$, and (3) rapid symptom response ("GO"), comprising $27.2 \%$ of participants, with a remission rate of $85.7 \%$. Higher baseline CDRS-R $(\mathrm{p}<0.001)$ and poorer functioning $(\mathrm{p}=0.03)$ were the strongest

Corresponding Author: David Brent, M.D., Western Psychiatric Institute and Clinic, 3811 O'Hara Street, Rm 311 Bellfield Towers, Pittsburgh, PA 15213, Phone: 412-246-5596, Fax: 412-246-5344, brentda@upmc.edu.

Conflict of Interest

Dr. Maalouf is on the Speaker's Bureau of Eli Lilly and participated in a meeting sponsored by Hikma pharmaceuticals.

Dr. Emslie has received research support from Biobehavioral Diagnostics, Eli Lilly, Forest Laboratories, GlaxoSmithKline, and Somerset. He has served as a consultant for Biobehavioral Diagnostics, Eli Lilly, Forest Laboratories, GlaxoSmithKline, Pfizer, and Wyeth Pharmaceuticals.

Dr. Wagner receives honoraria from Physicians Postgraduate Press, CMP Medica, Contemporary Forums, Quantia Communications, American Psychiatric Association, American Academy of Child and Adolescent Psychiatry, CME LLC.

Dr. Asarnow reports receiving unrestricted research support from Phillip Morris and consulting on cognitive-behavior therapy and depression quality improvement.

Dr. Keller is currently a professor of Psychiatry and Human Behavior at Brown University School of Medicine, has been a consultant and received honoraria from CENEREX, Medtronic, Sierra Neuropharmaceuticals, and has received grant funding from Pfizer. Dr. Birmaher is currently employed by the University of Pittsburgh and the University of Pittsburgh Medical Center/Western Psychiatric Institute and Clinic; has received research funding from the National Institute of Mental Health; is a consultant for Schering Plough; and has received royalties from Random House, Inc. (New Hope for Children and Teens with Bipolar Disorder) and Lippincott Williams \& Wilkins (Treating Child and Adolescent Depression).

Dr. Brent is currently employed by the University of Pittsburgh, School of Medicine and the University of Pittsburgh Medical Center, Western Psychiatric Institute and Clinic; has received research support from the National Institute of Mental Health; receives royalties from Guilford Press; and serves as UpToDate Psychiatry Editor.

Drs. Vitiello, Clarke, Spirito, Ryan, Shamseddeen, Iyengar, Ms. Mayes, and Ms. Porta report no potential conflicts of interest. 
discriminators between NO and GO. Higher baseline CDRS ( $\mathrm{p}<0.001)$ and scores on the Mania Rating Scale (MRS) ( $\mathrm{p}=0.01$ ) were the strongest discriminators between SLOW and GO. Other variables differentiating GO from both $\mathrm{NO}$ and from SLOW, were better baseline functioning, lower hopelessness, and lower family conflict. Both NO and SLOW showed increases on the MRS over time compared to GO (ps $\unlhd .04$ ), and increasing MRS was strongly associated with lack of remission by 72 weeks $(\mathrm{p}=0.02)$.

Limitations-High rate of open treatment by the end of the follow-up period creates difficulty in drawing clear inferences about the long-term impact of initial randomization.

Conclusion-Along with depressive severity, sub-syndromal manic symptoms, at baseline, and over time emerged as important predictors and correlates of poor outcome in this sample. Further research is needed on the treatment of severe depression, and on the assessment and management of sub-syndromal manic symptoms in treatment resistant depression.

\section{Introduction}

Adolescent depression is a prevalent, often chronic, and recurrent condition, and a leading contributor to morbidity and mortality in this age group (Lewinsohn et al., 1998). After 12 weeks of treatment, only around $1 / 3$ of patients attain remission, and even by 72 weeks only around $60 \%$ of participants in both the Treatment of Adolescent Depression Study (TADS) and Treatment of SSRI-Resistant Depression in Adolescents (TORDIA) clinical trial had remitted (Brent et al., 2008; Kennard et al., 2009; March et al., 2004; Vitiello et al., 2010). Clinical predictors of poor outcome in acute treatment of adolescent depression include chronicity and severity of depression, comorbidity, suicidal ideation, hopelessness, and family discord (Brent et al., 1997; Curry et al., 2006; Wilkinson et al., 2009). Many predictors of poor outcome in the treatment of resistant depression are similar to predictors of response in treatment-naïve depressed adolescents, and include severity, family conflict, and non-suicidal self-injury, drug and alcohol use and greater dysfunction at baseline (Asarnow et al., 2009; Emslie et al., 2010; Vitiello et al., 2010). In addition to these established predictors, one variable that may contribute to treatment-resistance in adults is unrecognized bipolar symptomatology (Inoue et al., 2006), even at a subsyndromal level of symptomatology (Correa et al., 2010; Dudek et al., 2010).

The above-noted findings show that there are individual differences in response to evidencebased treatments for adolescent depression. These individual differences point to a complementary approach to predicting the response to treatment, namely, Latent Class Growth Analysis (LCGA), which identifies relatively homogeneous sub-populations of individuals that show similar patterns of symptomatic response. LCGA has the advantage over more conventional approaches like survival analysis, insofar as LCGA does not assume that all participants come from the same population or that the relationship between covariates and outcomes is homogeneous, assumptions that are frequently violated in intervention studies (Clogg, 1995; Vermunt and Magidson, 2002). The use of LCGA to identify distinct classes of symptom response trajectories in adolescent depression and identifying predictors of membership in these classes can inform clinicians, patients, and families about an expectable symptomatic course, and may identify treatment targets that could improve the trajectory of treatment response. To our knowledge, this report is the first application of LCGA to elucidate patterns of treatment response among depressed adolescents participating in a clinical trial.

In this paper, we aim to classify the TORDIA participants according to their change in depressive symptom severity over time. Our objectives are to determine: (1) whether there are distinct classes of trajectories of depressive symptoms during the treatment of resistant depression; (2) which baseline clinical, demographic and treatment variables differentiate 
these classes; and (3) what is the most parsimonious set of abovementioned baseline variables that predicts membership in each class.

\section{Methods}

\subsection{Design and participants}

The design, methods, and results of TORDIA have been reported in detail elsewhere (Asarnow et al., 2009; Brent et al., 2008, 2009; Emslie et al., 2010; Vitiello et al., 2010). In brief, TORDIA was a 6-site trial that randomized 334 participants with unipolar major depression that had not responded to one adequate trial of SSRI to one of four treatments for 12 weeks: a switch to another SSRI; a switch to venlafaxine; a switch to another SSRI with CBT, or a switch to venlafaxine with CBT. During the 12-week acute phase, medication was administered under double-blind conditions. Following the initial 12 weeks, responders (defined as a $\mathbf{2 5 0 \%}$ decrease in the Children's Depression Rating Scale-Revised (CDRS-R) (Poznanski et al., 1984) and a Clinical Global Impressions-Improvement Subscale (CGI-I) (Guy, 1976) $\_$were continued on the same blinded treatment for an additional 12 weeks. Non-responders entered 12 weeks of open treatment, consisting of an increase in the dose of the current medication, switch to another antidepressant, augmentation, and/or addition of CBT or other psychotherapy as clinically indicated. Between weeks 24 and 72, participants were treated in the community and reassessed at weeks 48 and 72. A total of 261/334 (78.1\%), 178/316 (56.3\%) and 164/294 (56.0\%) of eligible participants completed assessments at weeks 24,48 , and 72 respectively. This study was approved by each site's local IRB. All participants and their parents gave written informed assent and consent.

\subsection{Assessments}

Diagnostic assessment was conducted using the Schedule for Affective Disorders and Schizophrenia for School-Age Children-Present and Lifetime (K-SADS-PL) (Kaufman et al., 1997) which was administered at study entry and at weeks 12, 24, and 72. Depression severity was rated by independent evaluators (IE), blinded to treatment assignment using the CDRS-R before treatment and at weeks 6, 12, 24, 48 and 72. The adolescent version of the Longitudinal Interval Follow-up Evaluation (A-LIFE) (Keller et al., 1987) administered at weeks 12, 24, 48 and 72, was used to rate the week-by-week severity of depressive disorder for the previous 3-month-period. Clinical Global Impressions Severity (CGI-S) and improvement (CGI-I) scales (Guy, 1976) and the Children's Global Assessment Scale (CGAS) (Shaffer et al., 1983) were used to assess severity of illness, improvement and level of functioning respectively. The Beck Depression Inventory (BDI) (Beck and Steer, 1984), the Beck Hopelessness Scale (BHS) (Beck et al., 1974), Screen for Anxiety-Related Emotional Disorders (SCARED) (Birmaher et al., 1997), Conflict Behavior QuestionnaireAdolescent Report (CBQ-A) (Robin and Weiss, 1980), the Suicidal Ideation Questionnaire for Adolescents (SIQ Jr) (Reynolds, 1987) and the Drug Use Screening Inventory (DUSI) (Kirisci et al., 1995) were completed by participants at baseline and at weeks 6, 12, 24, 48 and 72. The Mania Rating Scale (MRS) (Axelson et al., 2003) was administered at baseline and weeks 12, 24 and 72. The MRS is a 12-item scale extracted from the K-SADS-PL, and has been shown to have high internal consistency, inter-rater reliability, and convergent validity (Axelson et al., 2003). Suicidal adverse events in TORDIA were defined as the new onset, or worsening of suicidal ideation, a suicidal threat, or a suicide attempt. In contrast, a non-suicidal self injury (NSSI) adverse event was defined as self-injurious behavior resulting in physical damage with no intent to die (Brent et al., 2009). Remission was defined as the absence of clinically significant symptoms of depression for at least 3 consecutive weeks on the A-LIFE (Rush et al., 2006). 


\subsection{Statistical analysis}

In order to identify classes of trajectories of depression as measured by the CDRS-R, we conducted Latent Class Growth Analysis (LCGA). To achieve linearity in the data, we applied a natural $\log$ transformation of CDRS-R. We started with a 1-class model then increased the number of classes until we reached the model with the best fit to the data, as determined by the Bayesian information Criteria (BIC), and Lo-Mendell-Rubin (LMR) Adjusted, and Parametric Bootstrapped Likelihood Ratio Tests (PBLRT). Once the classes of trajectories were identified, we compared them with respect to baseline demographic and clinical characteristics as well as treatment characteristics, e.g. CBT versus no CBT, sleep medications, etc. that varied across participants in the trial. We set alpha $=0.05$ for the main effects, and alpha $=0.017(0.05 / 3)$ for post-hoc pair-wise analyses to correct for multiple comparisons.

Finally, we used backward stepwise multinomial logistic regression in order to determine the most parsimonious set of predictors of membership in the different classes of trajectories based on the baseline variables associated with class membership, examining the effects of the different variables, class membership, and their interaction. Mixed effects regression models were also computed for mean MRS and number of items endorsed on the MRS. These models estimated the effects of class, rate of mean MRS or number of endorsed items on MRS change over time, and rate of change by class. An additional mixed effects regression model was also computed for the MRS over time comparing those who had remitted to those who had not. We repeated this analysis after excluding the 5 participants who developed possible or probable hypomania. LCGA was conducted using Mplus Version 5.21. Other statistical analyses were conducted using PASW Statistics 17.0 and STATA 11.2. Time to remission was calculated using the Kaplan-Meier method. We also conducted sensitivity analyses repeating the LCGA using CDRS-R only up to week 24 , a period for which we had high participant retention.

\section{Results}

\subsection{CDRS-R Trajectories}

1. General description of classes of trajectories: The LCGAmodel that best fits the data is a 3-class-modelwith the lowest BIC (compared to the 2-class and 4-class models) (BIC $=448.65)$, significant LMR adjusted $(\mathrm{p}=0.006)$, and PBLRT $(\mathrm{p}<0.001)$ (Table 1). The first class, with 83 participants $(24.8 \%)$, showed the least amount of change over time ("NO"). Participants in this class started with a CDRS$\mathrm{R}$ of 67 (95\% confidence interval [CI]: 64.9-69.2) at baseline and ended with a CDRS-R of 46 (95\% CI: 41.3-50.4) at week 72.Only 22/83 (25.3\%) of participants in the "NO" class remitted; thus, a median time to remission could not be computed using the Kaplan-Meier procedure (Figs. 1 and 2). The second class included 160 participants (47.9\%) and showed a slow course to remission ("SLOW"). Participants in this class started with a CDRS-R of 58 (95\% CI: 56.9-59.7) at baseline and ended with a CDRS-R of 26 (95\% CI: 24.9-28.2) at week 72 and took a median of 26 weeks (95\% CI: 21.4-30.6) to remit (Figs. 1 and 2).The third class included 91 participants (27.2\%) and showed a rapid achievement of remission ("GO"). Participants in this class started with a CDRS-R of 52 (95\% CI: 50.653.9), ended with a CDRS-R of 21 (95\% CI: 19.6-22.3) at week 72 and took a median of 13 weeks (95\% CI: 12.1-13.9) to remit (Figs. 1 and 2).

2. Baseline differences among classes (Table 2.)

2a. Characteristics of depression: The three classes differed on baseline depression severity as measured by CDRS-R, with $\mathrm{NO}>\mathrm{SLOW}>\mathrm{GO}(\mathrm{F}(2,331)=60.21$, 
$\mathrm{p}<0.001)$ and all pair-wise comparisons showed significant differences (psb0.001). Class differences were also found for duration of depression $(F(2,323)=3.01$, $\mathrm{p}=0.05)$. Post-hoc pair-wise comparisons showed that NO had a much longer duration than $\mathrm{GO}(\mathrm{p}=0.016)$.

2b. Comorbidity: The three classes differed with respect to the frequency of comorbid anxiety disorders at study entry $\left(\chi^{2}{ }_{2}=7.85, \mathrm{p}=0.02\right)$. Post-hoc pair-wise contrasts showed a higher rate of comorbid anxiety in NO vs. GO $\left(\chi^{2}{ }_{1}=7.57\right.$, $\mathrm{p}=0.006$ ).

2c. Symptoms on self-reports: Class differences were found for self-reported anxiety (SCARED) $(\mathrm{F}(2,327)=6.36, \mathrm{p}=0.002)$, with a significant pair-wise contrast showing higher SCARED in NO vs. SLOW $(\mathrm{p}=0.004)$ and $\mathrm{GO}(\mathrm{p}<0.01)$. Class differences were also found for self-reported suicidal ideation (SIQ-Jr) $(\mathrm{F}(2.325)=7.90, \mathrm{p}<0.001)$ and hopelessness $(\mathrm{BHS})(\mathrm{F}(2.324)=11.08, \mathrm{p}<0.001)$. Post-hoc comparisons revealed that NO showed higher SIQ-JR scores than both SLOW $(p=0.006)$ and GO $(p<0.001)$. For hopelessness (BHS), NO was higher than both SLOW $(\mathrm{p}=0.006)$ and GO $(\mathrm{p}<0.001)$ and SLOW was also higher than GO $(\mathrm{p}=0.009)$. In addition, classes differed in their baseline Mania Rating Scale (MRS) scores (Kruskal-Wallis $\mathrm{H}=6.66, \mathrm{df}=2 \mathrm{p}=0.04$ ) and number of manic symptoms reported on the MRS (Kruskal-Wallis $\mathrm{H}=7.76, \mathrm{df}=2, \mathrm{p}=0.02$ ). Post-hoc pair-wise contrasts showed higher MRS in SLOW vs. GO $(\chi 21=30.02, \mathrm{p}=0.009)$ in addition to more manic symptoms reported on the MRS in SLOW vs. GO $\left(\chi^{2}{ }_{1}=30.27\right.$, $\mathrm{p}=0.008)$.

2d. Past history of non-suicidal self injury (NSSI) and suicide attempts: While the three classes did not differ in their history of suicide attempts $(\mathrm{p}=0.95)$, class differences were found for history of nonsuicidal self injury $\left(\chi^{2}{ }_{1}=10.51, p=0.005\right)$. Post hoc comparison showed that the frequency of history of NSSI was higher in NO than in GO $\left(\chi^{2}{ }_{1}=10.40, p=0.001\right)$.

2e. Parent-child conflict: Class differences were found for family conflict as perceived by the adolescent and measured by the CBQ-A $F(2,324)=6.21, \mathrm{p}=0.002)$. Post-hoc pair-wise contrasts showed that both NO ( $\mathrm{p}<0.001)$ and SLOW ( $\mathrm{p}=0.006)$ had higher conflict scores than GO.

2f. Level of functioning: Class differences were found for level of functioning as measured by CGAS $(\mathrm{F}(2,328)=20.47, \mathrm{p}<0.001)$. Post-hoc comparisons showed that NO had worse functioning than both SLOW $(\mathrm{p}<0.001)$ and GO $(\mathrm{p}<0.001)$ and SLOW had worse functioning than GO $(\mathrm{p}=0.01)$.

2g. Parental history of bipolar disorder: Parental history of bipolar disorder (I, II, or NOS) was unrelated to class membership, $(\mathrm{p}=0.12)$, baseline MRS scores $(\mathrm{p}=0.56)$, or time to remission ( $\mathrm{ps}>0.16$ ).

3. Differences during treatment course (Table 3.):

3a. Response at week 6: Class differences were found for rate of response at week $6\left(\chi^{2}{ }_{2}=49.42, \mathrm{p}<0.001\right)$ with the lowest rate for $\mathrm{NO}(2.8 \%, 95 \%$ CI: $0.6-8.7)$, followed by SLOW $(24.3 \%, 95 \%$ CI: $17.8-31.9)$ and the highest rate for GO (53.1\%, 95\% CI: 42.3-63.7). All pair-wise contrasts were significant (psb0.017).

3c. Time to remission: Log-rank test showed an overall effect of class on time to remission: $\chi^{2}{ }_{2}=173.01, \mathrm{p}<0.001$, with NO $>$ SLOW: $\chi^{2}{ }_{1}=55.7, \mathrm{p}<0.001$, NO $>$ GO: $\chi^{2}{ }_{1}=124.41, p<0.001$, and SLOW $>$ GO: $\chi^{2}{ }_{1}=64.07, p<0.001$ (Fig. 2).

3d. Adverse Events: Participants in NO and SLOW were more likely to develop new-onset or worsening suicidal ideation during the first 12 weeks of treatment 
$\left(\chi^{2}{ }_{1}=6.56, p=0.01\right.$ for $\mathrm{NO}$ vs. GO and $\chi^{2}{ }_{1}=8.95, \mathrm{p}=0.002$ for SLOW vs. GO). No class differences were found for suicide attempts and non-suicidal self-injury (ps>0.2). There were 4 participants who developed possible or probable hypomanic episodes in "NO" (4.8\%), 1 in "SLOW (0.6\%) and none in "GO", Fisher's exact test, $\mathrm{p}=0.02$; no post-hoc pairwise differences were significant.

4. Predictors of Class Membership:

Backward stepwise multinomial logistic regression with NO, SLOW and GO as outcomes and including the following baseline predictors that were associated with class membership (CDRS-R, BDI, BHS, SIQ Jr, SCARED, CBQ-A, CGI-S, CGAS, MRS, duration of depression, history of Non-Suicidal Self Injury (NSSI) and comorbid anxiety disorders) identified higher baseline CDRS $(\beta=0.16,95 \%$ confidence interval $[\mathrm{CI}]: 0.11-0.21, \mathrm{z}=6.32, \mathrm{p}<0.001)$, and lower CGAS $(\beta=-0.06$, 95\% CI: -0.12 to $-0.01, \mathrm{z}=-2.17, \mathrm{p}=0.03)$ as the best predictors of $\mathrm{NO}$ as compared to $\mathrm{GO}$ whereas higher baseline CDRS ( $\beta=0.07,95 \%$ CI: $0.03-0.11, \mathrm{z}=3.51, \mathrm{p}<$. $001)$ and higher baseline MRS ( $\beta=0.10,95 \%$ CI: $0.02-0.17, z=2.56, p=0.01)$ were the best predictors of SLOW as compared to GO.

When number of manic symptoms endorsed on the MRS instead of mean MRS was entered in the regression model, higher baseline CDRS ( $\beta=0.16,95 \%$ CI: $0.11-0.20, \mathrm{z}=6.30$, $\mathrm{p}<0.001)$, higher baseline BDI $(\beta=0.05,95 \%$ CI: $0.01-0.09, \mathrm{z}=2.67, \mathrm{p}=0.008)$ and longer duration of depression $(\beta=0.02,95 \%$ CI: $0.00-0.04, \mathrm{z}=2.06, \mathrm{p}=0.04)$ predicted NO as compared to GO, and higher CDRS ( $\beta=0.06,95 \%$ CI: $0.02-0.10, \mathrm{z}=3.12, \mathrm{p}=0.002)$, and higher number of manic symptoms $(\beta=0.12,95 \%$ CI: $0.02-0.22, \mathrm{z}=2.36, \mathrm{p}=0.018)$ predicted SLOW as compared to GO.

Because there were baseline differences among the 3 classes with respect to MRS, we examined the change in MRS over time as a function of class. The mixed effects regression model of MRS showed a class effect $(\mathrm{p}=0.006)$ and a logtime*class interaction $(\mathrm{p}=\mathrm{b} 0.001)$ (Fig. 3). Here, worsening (increasing) MRS scores were associated with membership in NO relative to both SLOW (SLOW* $\log$ time interaction pb0.001) and to $\mathrm{GO}\left(\mathrm{GO}^{*} \log\right.$ time interaction, $\mathrm{p}=0.04$ ). We also examined the relationship of MRS over time in those who did and did not remit and found that worsening manic symptoms over time (i.e. increasing MRS) was associated with lack of remission (remission*logtime interaction, $\mathrm{p}=0.02$ ). These results were similar when the number of manic symptoms was used rather than the MRS score (Fig. 4) and did not change when the 5 participants who developed possible or probable hypomania were removed.

\subsection{Additional results}

Given a $44 \%$ rate of attrition after week 24 , we conducted sensitivity analysis repeating the LCGA using CDRS-R up to week 24 and obtained 3 trajectories similar to those we presented above (NO, GO and SLOW). There was an $83.5 \%$ agreement ( $\kappa=0.74,95 \%$ CI: 0.67-0.80) between class membership from the LCGA model that included CDRS-R up to week 72 and the one with CDRS-R up to week 24 , and predictors and correlates of trajectory membership were very similar.

\section{Discussion}

We identified three classes of symptom response in treatment-resistant depressed adolescents using latent classification analysis. One class, "GO," showed a rapid initial response and a short time to remission, around 3 months. A second class, "SLOW," showed a slower response, with a median time to remission of 6 months. The third class, "NO," consisted predominantly of participants who were unlikely to attain remission even 72 
weeks after intake. These trajectories were well established after 6 weeks of treatment. In addition to depression severity, anxiety, hopelessness, and family conflict, sub-syndromal manic symptomology emerged as a predictor and correlate of trajectory. Higher baseline manic symptoms predicted a slower rate of remission. Over time, an increased number of manic symptoms were associated with the "NO" class and with lack of remission, even after those few participants who became hypomanic were excluded from the analyses.

To our knowledge, this is the first study in adolescent depression to report that subsyndromal manic symptoms may contribute to poor outcome in adolescent depression treatment. While baseline MRS scores only discriminated SLOW from GO, higher MRS scores over time were found in both NO and SLOW, compared to GO, and were associated with lack of remission. Although this is a novel finding in adolescents, it is convergent with a growing literature in adults linking sub-syndromal bipolar symptoms to treatmentresistant depression (Correa et al., 2010), with initial reports on this topic as long as 2 decades ago (Akiskal and Mallya, 1987). Later studies showed that the rate of bipolar spectrum disorders can reach more than 50\% in treatment-resistant populations diagnosed with unipolar MDD when in-depth assessments and modified criteria are used, especially in referred samples (Hantouche et al., 1998; Sharma et al., 2005). Even epidemiological studies have reported that as many as $40 \%$ of participants with a history of MDD had a history of subthreshold hypomanic symptoms, which in turn was associated with a younger age at onset, more episodes of depression, and higher rates of comorbidity (Angst et al., 2010). These findings in adults complement epidemiological studies of adolescents showing that as much as $6 \%$ of community youth have "soft" bipolar symptoms with markedly greater rates of comorbidity, suicidal behavior and functional impairment compared to unipolar depressed adolescents without manic symptoms (Lewinsohn et al., 1995). In the present study, the mean MRS scores for the three classes were between 3 and 5 , well below the clinical cut-off score $(=12)$ for bipolar disorder in children and adolescents (Axelson et al., 2003). In addition, DSM-IV bipolar spectrum disorder was an exclusion criterion for TORDIA. These findings suggest that the presence of manic symptoms, even below the level that we currently consider clinically significant, may characterize a subpopulation of adolescents with treatmentresistant depression who are unlikely to respond to the currently available evidence-based depression treatment. Studies using mood stabilizers, either alone or as an augmenting agent are worth strong consideration in this population. However, similar to the findings of Lewinsohn et al. (2000), family history of bipolar disorder was not related to the number or severity of manic symptoms in this sample.

These findings also provide additional support for the importance of the first few weeks of treatment in determining long-term outcome, which appears to be true both in treatment resistant adolescent samples, as well as in those who were treatment naïve (Asarnow et al., 2009; Tao et al., 2009; Vitiello et al., 2010). A slower pace of response is clinically significant because the slower the treatment response, the greater the likelihood of the occurrence of a suicidal event. Since the majority of suicidal events occur early in the course of treatment, acceleration of initial treatment response may not only improve the rate of remission, but also decrease rate of suicidal events, as is suggested by the findings in TADS as well as experimental studies to accelerate treatment response in suicidal adult patients with treatmentresistant depression with ketamine (Price et al., 2009). In addition, the characteristics of the treatment refractory group, such as high rates of family conflict anxiety, non-suicidal self-injury, and high hopelessness, could also suggest additional treatment targets to improve the response and remission rates.

This sample of treatment resistant depressed adolescents is one that was unlikely to remit spontaneously, both because they had been ill a median of two years prior to entry into the study, and because to enter the study, participants had to have two assessments and 
demonstrate symptom stability prior to randomization. Therefore, these findings may be particularly relevant for chronically ill, treatment resistant depressed adolescents. These findings indicate that while our current treatments, including combination of antidepressants and cognitive behavior therapy, were able to help most treatment resistant adolescents, a sub-group, with particularly high baseline CDRS-R scores, often did not respond to evidence-based treatments, similar to findings in other large clinical trials (Goodyer et al., 2007; March et al., 2004).

Limitations of this study include a high rate of open treatment by the end of the follow-up period, making it difficult to draw clear inferences about the long-term impact of initial randomization. There was also a fairly high rate of attrition, especially from 24 to 72 weeks of follow-up. Since the three-class solution was also found when limiting the analyses to the first 24 weeks, when we had good (78\%) participant retention, we can infer that these findings were not unduly influenced by drop-out. In addition, in the Mplus implementation of LCGA, missing data are handled in accord with the approach of Little and Rubin (2002). Missing data are modeled as missing at random (MAR). Simulation studies byCollins et al. (2001) show that the MAR assumption gives results with modest degrees of bias and loss of efficiency even when the missingness is not at random (MNAR). Therefore, the results that we report have taken into account and are likely robust to the effects of attrition.

Another limitation is that there may be other important domains for which we had no formal assessment that could determine trajectories of symptoms in resistant depression. For example, domains such as neurocognitive deficits have been shown to be present in pediatric depression and to predict treatment response in depressed adults (Dunkin et al., 2000; Maalouf et al., 2011).

In summary, we identified three classes of trajectories of depressive symptoms in TORDIA participants using latent classification analysis (LCGA): rapid remitters, slow remitters, and those who were unlikely to remit. Depression severity, lower level of functioning, longer duration of depression and presence of manic symptoms predicted membership in a class with less favorable outcome. In addition, suicidal adverse events were more likely to occur in members of the trajectories with less favorable course. These findings may have important clinical and research implications. Clinicians who are treating adolescents with treatment-resistant MDD should assess for the presence of manic symptoms at baseline and during the treatment course even in individuals in whom the diagnosis of bipolar disorder has been ruled out. Although prospective studies of bipolar youth have already challenged the time criteria currently in use for defining clinically significant manic symptoms (Birmaher et al., 2009), it is important to emphasize that the presence of sub-syndromal manic symptoms in youths does not necessarily indicate the presence of bipolar disorder per se (Findling et al., 2010). Indeed, in the Longitudinal Assessment of Manic Symptoms Study (LAMS) sample, not all children with elevated manic symptoms had bipolar disorder although those with persistently elevated manic symptoms were more likely to have bipolar spectrum disorders (Frazier et al., 2011). In conclusion, this study supports the importance of understanding the clinical significance of sub-syndromal manic symptoms and the need for further research into the use of mood stabilizers for the management of treatment resistant depression in adolescents.

\section{Acknowledgments}

Role of Funding Source

Funded by NIMH grants MH61835 (Pittsburgh); MH61856 (Galveston); MH61864 (UCLA); MH61869 (Portland); MH61958 (Dallas); and MH62014 (Brown), and the Advanced Center for Early-Onset Mood and Anxiety Disorders (MH66371, PI: David Brent, MD). 
We wish to thank the youth, families and staff who made this project possible.

\section{References}

Akiskal HS, Mallya G. Criteria for the "soft" bipolar spectrum: treatment implications. Psychopharmacology Bulletin. 1987; 23:68-73. [PubMed: 3602332]

Angst J, Cui L, Swendsen J, Rothen S, Cravchik A, Kessler RC, Merikangas KR. Major depressive disorder with subthreshold bipolarity in the National Comorbidity Survey Replication. The American Journal of Psychiatry. 2010; 167:1194-1201. [PubMed: 20713498]

Asarnow JR, Emslie G, Clarke G, Wagner KD, Spirito A, Vitiello B, Iyengar S, Shamseddeen W, Ritz L, McCracken J, Strober M, Suddath R, Leonard H, Porta G, Keller M, Brent D. Treatment of selective serotonin reuptake inhibitor-resistant depression in adolescents: predictors and moderators of treatment response. Journal of the American Academy of Child and Adolescent Psychiatry. 2009; 48:330-339. [PubMed: 19182688]

Axelson D, Birmaher BJ, Brent D, Wassick S, Hoover C, Bridge J, Ryan N. A preliminary study of the Kiddie Schedule for Affective Disorders and Schizophrenia for School-Age Childrenmania rating scale for children and adolescents. Journal of Child and Adolescent Psychopharmacology. 2003; 13:463-470. [PubMed: 14977459]

Beck AT, Steer RA. Internal consistencies of the original and revised Beck Depression Inventory. Journal of Clinical Psychology. 1984; 40:1365-1367. [PubMed: 6511949]

Beck AT, Weissman A, Lester D, Trexler L. The measurement of pessimism: the hopelessness scale. Journal of Consulting and Clinical Psychology. 1974; 42:861-865. [PubMed: 4436473]

Birmaher B, Khetarpal S, Brent D, Cully M, Balach L, Kaufman J, Neer SM. The Screen for Child Anxiety Related Emotional Disorders (SCARED): scale construction and psychometric characteristics. Journal of the American Academy of Child and Adolescent Psychiatry. 1997; 36:545-553. [PubMed: 9100430]

Birmaher B, Axelson D, Goldstein B, Strober M, Gill MK, Hunt J, Houck P, Ha W, Iyengar S, Kim E, Yen S, Hower H, Esposito-Smythers C, Goldstein T, Ryan N, Keller M. Four-year longitudinal course of children and adolescents with bipolar spectrum disorders: the Course and Outcome of Bipolar Youth (COBY) study. The American Journal of Psychiatry. 2009; 166:795-804. [PubMed: 19448190]

Brent DA, Holder D, Kolko D, Birmaher B, Baugher M, Roth C, Iyengar S, Johnson BA. A clinical psychotherapy trial for adolescent depression comparing cognitive, family, and supportive therapy. Archives of General Psychiatry. 1997; 54:877-885. [PubMed: 9294380]

Brent D, Emslie G, Clarke G, Wagner KD, Asarnow JR, Keller M, Vitiello B, Ritz L, Iyengar S, Abebe K, Birmaher B, Ryan N, Kennard B, Hughes C, Debar L, McCracken J, Strober M, Suddath R, Spirito A, Leonard H, Melhem N, Porta G, Onorato M, Zelazny J. Switching to another SSRI or to venlafaxine with or without cognitive behavioral therapy for adolescents with SSRI-resistant depression: the TORDIA randomized controlled trial. JAMA : The Journal of the American Medical Association. 2008; 299:901-913. [PubMed: 18314433]

Brent DA, Emslie GJ, Clarke GN, Asarnow J, Spirito A, Ritz L, Vitiello B, Iyengar S, Birmaher B, Ryan ND, Zelazny J, Onorato M, Kennard B, Mayes TL, Debar LL, McCracken JT, Strober M, Suddath R, Leonard H, Porta G, Keller MB. Predictors of spontaneous and systematically assessed suicidal adverse events in the treatment of SSRI-resistant depression in adolescents (TORDIA) study. The American Journal of Psychiatry. 2009; 166:418-426. [PubMed: 19223438]

Clogg, C. Latent class models. In: Arminger, G.; Clogg, C.; Sobel, M., editors. Handbook of Statistical Modeling for the Social and Behavioral Sciences. New York: Plenum Press; 1995.

Collins LM, Schafer JL, Kam CM. A comparison of inclusive and restrictive strategies in modern missing data procedures. Psychological Methods. 2001; 6:330-351. [PubMed: 11778676]

Correa R, Akiskal H, Gilmer W, Nierenberg AA, Trivedi M, Zisook S. Is unrecognized bipolar disorder a frequent contributor to apparenttreatment resistant depression? Journal of Affective Disorders. 2010; 127:10-18. [PubMed: 20655113]

Curry J, Rohde P, Simons A, Silva S, Vitiello B, Kratochvil C, Reinecke M, Feeny N, Wells K, Pathak S, Weller E, Rosenberg D, Kennard B, Robins M, Ginsburg G, March J. Predictors and moderators of acute outcome in the Treatment for Adolescents with Depression Study (TADS). Journal of the 
American Academy of Child and Adolescent Psychiatry. 2006; 45:1427-1439. [PubMed: 17135988]

Dudek D, Rybakowski JK, Siwek M, Pawlowski T, Lojko D, Roczen R, Kiejna A. Risk factors of treatment resistance in major depression: association with bipolarity. Journal of Affective Disorders. 2010; 126:268-271. [PubMed: 20381154]

Dunkin JJ, Leuchter AF, Cook IA, Kasl-Godley JE, Abrams M, Rosenberg-Thompson S. Executive dysfunction predicts nonresponse to fluoxetine in major depression. Journal of Affective Disorders. 2000; 60:13-23. [PubMed: 10940443]

Emslie GJ, Mayes T, Porta G, Vitiello B, Clarke G, Wagner KD, Asarnow JR, Spirito A, Birmaher B, Ryan N, Kennard B, Debar L, McCracken J, Strober M, Onorato M, Zelazny J, Keller M, Iyengar S, Brent D. Treatment of Resistant Depression in Adolescents (TORDIA): week 24 outcomes. The American Journal of Psychiatry. 2010; 167:782-791. [PubMed: 20478877]

Findling RL, Youngstrom EA, Fristad MA, Birmaher B, Kowatch RA, Arnold LE, Frazier TW, Axelson D, Ryan N, Demeter CA, Gill MK, Fields B, Depew J, Kennedy SM, Marsh L, Rowles BM, Horwitz SM. Characteristics of children with elevated symptoms of mania: the Longitudinal Assessment of Manic Symptoms (LAMS) study. The Journal of Clinical Psychiatry. 2010; 71:1664-1672. [PubMed: 21034685]

Frazier TW, Youngstrom EA, Mccue Horwitz S, Demeter CA, Fristad MA, Arnold LE, Birmaher B, Kowatch RA, Axelson D, Ryan N, Gill MK, Findling RL. Relationship of persistent manic symptoms to the diagnosis of pediatric bipolar spectrum disorders. The Journal of Clinical Psychiatry. 2011; 72:846-853. [PubMed: 21457674]

Goodyer I, Dubicka B, Wilkinson P, Kelvin R, Roberts C, Byford S, Breen S, Ford C, Barrett B, Leech A, Rothwell J, White L, Harrington R. Selective serotonin reuptake inhibitors (SSRIs) and routine specialist care with and without cognitive behaviour therapy in adolescents with major depression: randomised controlled trial. BMJ. 2007; 335:106-107. [PubMed: 17641303]

Guy, W. ECDEU Assessment Manual for the Psychopharmacology. 2nd ed. Washington, DC: Dept. of Health and Human Services Publication; 1976.

Hantouche EG, Akiskal HS, Lancrenon S, Allilaire JF, Sechter D, Azorin JM, Bourgeois M, Fraud JP, Chatenet-Duchene L. Systematic clinical methodology for validating bipolar-II disorder: data in midstream from a French national multi-site study (EPIDEP). Journal of Affective Disorders. 1998; 50:163-173. [PubMed: 9858076]

Inoue T, Nakagawa S, Kitaichi Y, Izumi T, Tanaka T, Masui T, Kusumi I, Denda K, Koyama T. Longterm outcome of antidepressantrefractory depression: the relevance of unrecognized bipolarity. Journal of Affective Disorders. 2006; 95:61-67. [PubMed: 16797078]

Kaufman J, Birmaher B, Brent D, Rao U, Flynn C, Moreci P, Williamson D, Ryan N. Schedule for Affective Disorders and Schizophrenia for School-Age Children-Present and Lifetime Version (K-SADS-PL): initial reliability and validity data. Journal of the American Academy of Child and Adolescent Psychiatry. 1997; 36:980-988. [PubMed: 9204677]

Keller MB, Lavori PW, Friedman B, Nielsen E, Endicott J, McDonald-Scott P, Andreasen NC. The Longitudinal Interval Follow-up Evaluation. A comprehensive method for assessing outcome in prospective longitudinal studies. Archives of General Psychiatry. 1987; 44:540-548. [PubMed: 3579500]

Kennard BD, Silva SG, Tonev S, Rohde P, Hughes JL, Vitiello B, Kratochvil CJ, Curry JF, Emslie GJ, Reinecke M, March J. Remission and recovery in the Treatment for Adolescents with Depression Study (TADS): acute and long-term outcomes. Journal of the American Academy of Child and Adolescent Psychiatry. 2009; 48:186-195. [PubMed: 19127172]

Kirisci L, Mezzich A, Tarter R. Norms and sensitivity of the adolescent version of the drug use screening inventory. Addictive Behaviors. 1995; 20:149-157. [PubMed: 7484309]

Lewinsohn PM, Klein DN, Seeley JR. Bipolar disorders in a community sample of older adolescents: prevalence, phenomenology, comorbidity, and course. Journal of the merican Academy of Child and Adolescent Psychiatry. 1995; 34:454-463.

Lewinsohn PM, Rohde P, Seeley JR. Major depressive disorder in older adolescents: prevalence, risk factors, and clinical implications. Clinical Psychology Review. 1998; 18:765-794. [PubMed: 9827321] 
Lewinsohn PM, Klein DN, Seeley JR. Bipolar disorder during adolescence and young adulthood in a community sample. Bipolar Disorders. 2000; 2:281-293. [PubMed: 11249806]

Little, R.; Rubin, D. Statistical Analysis with Missing Data. Wiley; 2002.

Maalouf FT, Brent D, Clark L, Tavitian L, Mchugh RM, Sahakian BJ, Phillips ML. Neurocognitive impairment in adolescent major depressive disorder: state vs. trait illness markers. Journal of Affective Disorders. 2011; 133:625-632. [PubMed: 21620477]

March J, Silva S, Petrycki S, Curry J, Wells K, Fairbank J, Burns B, Domino M, Mcnulty S, Vitiello B, Severe J. Fluoxetine, cognitive-behavioral therapy, and their combination for adolescents with depression: Treatment for Adolescents With Depression Study (TADS) randomized controlled trial. JAMA : The Journal of the American Medical Association. 2004; 292:807-820. [PubMed: 15315995]

Poznanski EO, Grossman JA, Buchsbaum Y, Banegas M, Freeman L, Gibbons R. Preliminary studies of the reliability and validity of the children's depression rating scale. Journal of the American Academy of Child Psychiatry. 1984; 23:191-197. [PubMed: 6715741]

Price RB, Nock MK, Charney DS, Mathew SJ. Effects of intravenous ketamine on explicit and implicit measures of suicidality in treatment-resistant depression. Biological Psychiatry. 2009; 66:522-526. [PubMed: 19545857]

Reynolds, W. Professional Manual for the Suicidal Ideation Questionnaire. Lutz, FL: Psychological Assessment Resources, Inc; 1987.

Robin AL, Weiss JG. Criterion-related validity of behavioral and selfreport measures of problemsolving communication skills in distressed and non-distressed parent-adolescent dyads. Behavior Assessment. 1980; 2:339-352.

Rush AJ, Kraemer HC, Sackeim HA, Fava M, Trivedi MH, Frank E, Ninan PT, Thase ME, Gelenberg AJ, Kupfer DJ, Regier DA, Rosenbaum JF, Ray O, Schatzberg AF. Report by the ACNP Task Force on response and remission in major depressive disorder. Neuropsychopharmacology. 2006; 31:1841-1853. [PubMed: 16794566]

Shaffer D, Gould MS, Brasic J, Ambrosini P, Fisher P, Bird H, Aluwahlia S. A Children's Global Assessment Scale (CGAS). Archives of General Psychiatry. 1983; 40:1228-1231. [PubMed: 6639293]

Sharma V, Khan M, Smith A. A closer look at treatment resistant depression: is it due to a bipolar diathesis? Journal of Affective Disorders. 2005; 84:251-257. [PubMed: 15708423]

Tao R, Emslie G, Mayes T, Nakonezny P, Kennard B, Hughes C. Early prediction of acute antidepressant treatment response and remission in pediatric major depressive disorder. Journal of the American Academy of Child and Adolescent Psychiatry. 2009; 48:71-78. [PubMed: 19057412]

Vermunt, J.; Magidson, J. Latent class cluster analysis. In: Hagenaars, J.; McCutcheon, A., editors. Applied Latent Class Models. Cambridge, UK: Cambridge University Press; 2002.

Vitiello B, Emslie G, Clarke G, Wagner KD, Asarnow JR, Keller MB, Birmaher B, Ryan ND, Kennard B, Mayes TL, Debar L, Lynch F, Dickerson J, Strober M, Suddath R, McCracken JT, Spirito A, Onorato M, Zelazny J, Porta G, Iyengar S, Brent DA. Long-term outcome of adolescent depression initially resistant to selective serotonin reuptake inhibitor treatment: a follow-up study of the TORDIA sample. The Journal of Clinical Psychiatry. 2010; 72:388-396. [PubMed: 21208583]

Wilkinson P, Dubicka B, Kelvin R, Roberts C, Goodyer I. Treated depression in adolescents: predictors of outcome at 28 weeks. The British Journal of Psychiatry. 2009; 194:334-341. [PubMed: 19336785] 


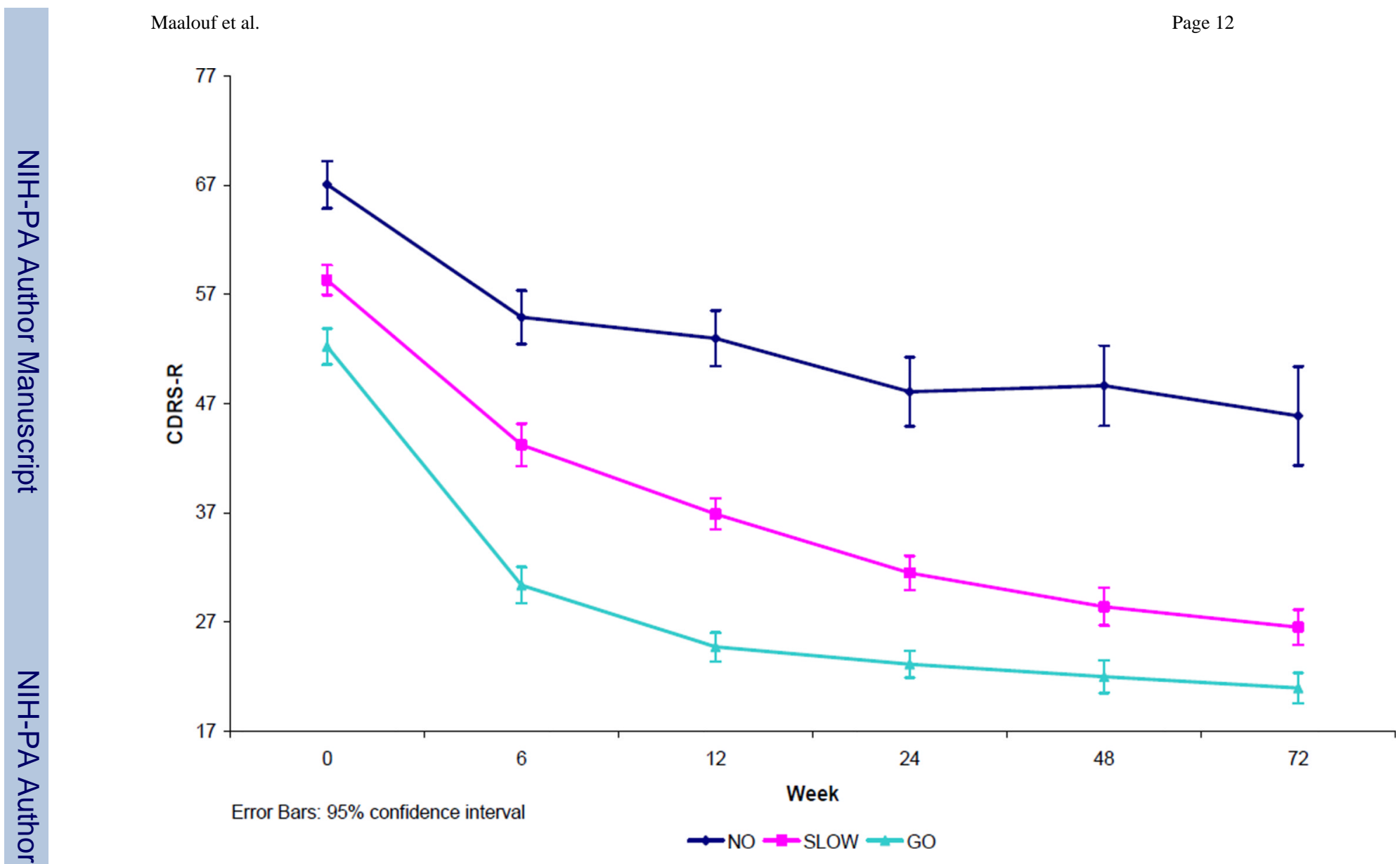

Fig.1.

CDRS-R Trajectories in TORDIA: "No", "SLOW" and "GO" Classes. 
Kaplan Meier Survival Curve by Class

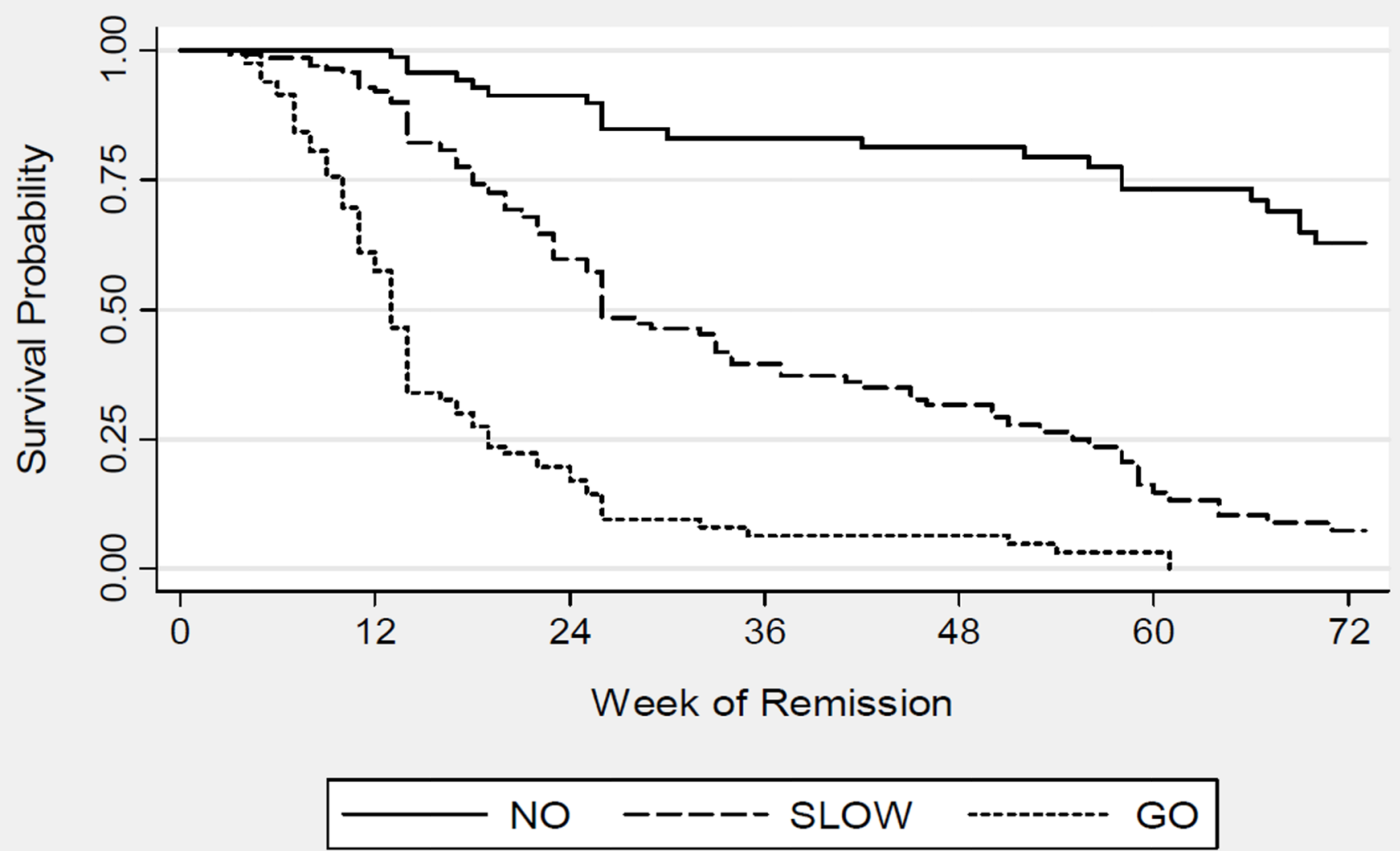

Fig.2.

Kaplan Meir Survival Curve by Class: Time to Remission 

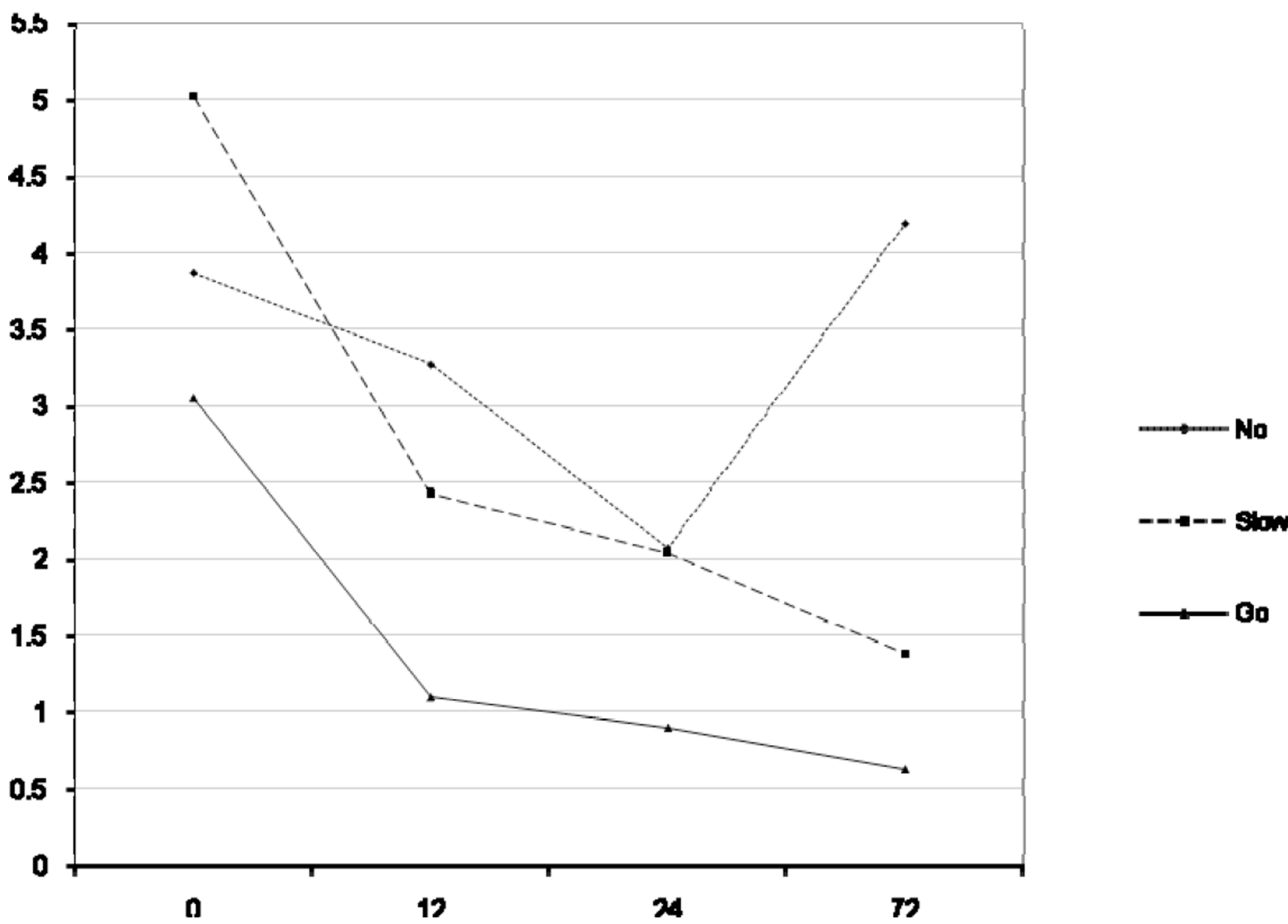

Fig 3.

Mean Mania Rating Scale (MRS) by Class Over Time

Class: $\operatorname{chi} 2(2)=10.25, \mathrm{p}=0.006$, Class*week: $\operatorname{chi} 2(2)=14.15, \mathrm{p}<0.001$, SLOW $^{*}$ logtime $(\beta=$ $-0.71,95 \% \mathrm{CI}:-1.01--0.34, \mathrm{z}=-3.76, \mathrm{p}<0.001)$ and $\mathrm{GO} * \log \operatorname{time}(\beta=-0.43,95 \% \mathrm{CI}$ : $-0.85--0.017, \mathrm{z}=-2.043 .76, \mathrm{p}<0.041)$. 


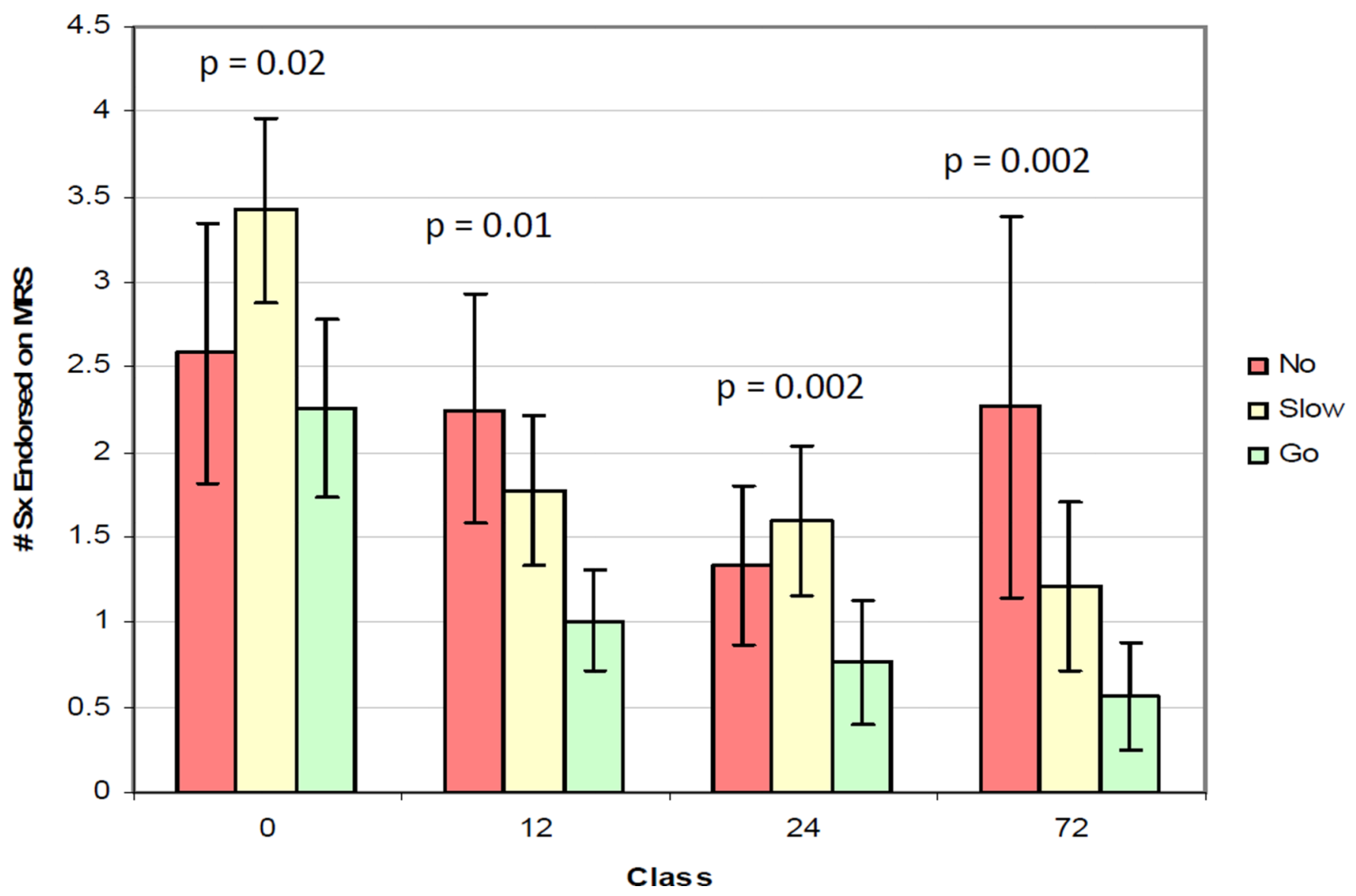

Fig 4.

Number of Endorsed Manic Symptoms by Class Over Time

The mixed effects regression model of number of items endorsed on the MRS showed a class effect $(\mathrm{p}=0.003)$ and a logtime*class interaction $(\mathrm{p}=<0.001)$. Here, more items on MRS were associated with membership in NO relative to both SLOW (SLOW * $\log$ time interaction: IRR $=0.81,95 \% \mathrm{CI}: 0.72-0.92, \mathrm{z}=-3.34, \mathrm{p} \leq 0.001)$ and to $\mathrm{GO}(\mathrm{GO} * \log$ time: IRR $=0.75,95 \%$ CI:0.65-0.87, $\mathrm{z}=-3.80, \mathrm{p} \leq 0.001$ ) 


\section{Table 1}

Fit statistics for latent class analysis identifying classes: CDRS-R Trajectories in TORDIA

\begin{tabular}{|c|c|c|c|c|}
\hline Model & $\mathrm{BIC}^{\dagger}$ & $\begin{array}{c}\text { Adjusted } \\
\text { LMR }^{\dagger} \\
\text { (P-value) }\end{array}$ & $\begin{array}{l}\operatorname{PBLRT}^{\S} \\
\text { (P-value) }\end{array}$ & $\begin{array}{l}\text { Number of cases per } \\
\text { class }\end{array}$ \\
\hline 1-Class & 819.972 & -- & -- & 334 \\
\hline 2-Class & 473.217 & $<0.001$ & $<0.001$ & $109-225$ \\
\hline 3-Class & 448.649 & 0.006 & $<0.001$ & 83-160-91 \\
\hline 4-Class & 455.735 & 0.055 & & $8-162-81-83$ \\
\hline \multicolumn{5}{|c|}{ BIC stands for Bayesian information Criteria } \\
\hline \multicolumn{5}{|c|}{ LMR stands for Lo-Mendell Rubin Adjusted Likelihood Ratio Test } \\
\hline
\end{tabular}




\section{Table 2}

Demographic and Clinical Characteristics by Class *

\begin{tabular}{|c|c|c|c|c|}
\hline & & Class & & \\
\hline & $\begin{array}{c}\text { NO } \\
(\mathbf{N}=83)\end{array}$ & $\begin{array}{l}\text { SLOW } \\
(\mathbf{N}=160)\end{array}$ & $\begin{array}{c}\text { GO } \\
(\mathbf{N}=91)\end{array}$ & $\mathbf{p}$ \\
\hline Age $(\mathrm{M}, \mathrm{SD})^{* *}$ & $15.7(1.3)$ & $15.9(1.6)$ & $16.0(1.6)$ & 0.57 \\
\hline Sex $(\mathrm{N}, \%$ Female $)$ & $61(73.5)$ & $113(70.6)$ & $59(64.8)$ & 0.44 \\
\hline Race (N, \% White) & $64(77.1)$ & $135(84.4)$ & $78(85.7)$ & 0.26 \\
\hline Parental Education (N, \% $\geq$ College grad) & $35(43.2)$ & $74(49.0)$ & $43(50.0)$ & 0.63 \\
\hline Income (in thousands) (Median, Range) & $49(10-500)$ & $60(8-250)$ & $65(0-400)$ & 0.61 \\
\hline Duration of Depression (in months) (M, SD) & $26.0(22.3)^{\dagger}$ & $22.9(21.9)^{\dagger, t}$ & $18.4(14.5)^{f}$ & 0.05 \\
\hline Age at onset of MDD Symptoms (M, SD) & $12.7(2.5)$ & $12.5(2.5)$ & $13.1(2.6)$ & 0.30 \\
\hline Age at onset current MDD (M, SD) & $13.6(2.1)$ & $13.8(2.3)$ & $14.3(2.1)$ & 0.07 \\
\hline Children's Depression rating Scale - Revised M(SD) & $67.1(10.1)^{\dagger}$ & $58.3(8.8)^{\mathcal{\xi}}$ & $52.2(8.0)^{t}$ & $<0.001$ \\
\hline Beck Depression Inventory - Adolescent (M, SD) & $27.8(13.0)^{\dagger}$ & $20.1(10.5)^{\mathcal{\xi}}$ & $14.6(10.3)^{f^{t}}$ & $<0.001$ \\
\hline Children's Global Assessment Scale, M(SD) & $46.5(7.6)^{\dagger}$ & $51.1(7.0)^{\mathcal{S}}$ & $53.5(7.5)^{. t}$ & $<0.001$ \\
\hline Clinical Global Impressions - Severity (M, SD) & $4.7(0.7)^{\dagger}$ & $4.5(0.7)^{\xi}$ & $4.2(0.5)^{f^{t}}$ & $<0.001$ \\
\hline Beck Hopelessness Scale (M, SD) & $12.6(5.9)^{\dagger}$ & $10.5(5.3)^{\xi}$ & $8.7(5.4)^{t}$ & $<0.001$ \\
\hline Screen for Child Anxiety Related Disorders (M, SD) & $34.9(15.8)^{\dagger}$ & $28.6(15.0)^{t^{t}}$ & $26.8(16.2)^{t}$ & 0.002 \\
\hline History of Suicide Attempt (N, \% Yes) & $19(22.9)$ & $39(24.5)$ & $21(23.1)$ & 0.95 \\
\hline History of NSSI (N, \% Yes) & $40(49.4)^{\dagger}$ & $62(39.5)^{\dagger, t}$ & $23(25.6)^{t}$ & 0.005 \\
\hline Suicidal Ideation (M, SD) & $49.1(24.5)^{\dagger}$ & $40.9(21.5) *$ & $36.0(19.7)^{*}$ & $<0.001$ \\
\hline Drug Use Screening Inventory - Use (N, \%Yes) & $40(49.4)$ & $87(54.7)$ & $52(57.8)$ & 0.54 \\
\hline Mania Rating Scale (M, SD) & $3.9(4.9)^{\dagger}$ & $5.0(5.2)^{\dagger}$ & $3.1(3.2) \cdot t$ & 0.04 \\
\hline Comorbid Anxiety Disorders $\boldsymbol{s}_{(\mathrm{N}, \% \text { Yes })}$ & $39(48.1)^{\dagger}$ & $56(35.2)^{\hat{f}, t}$ & $24(27.6)^{* t}$ & 0.02 \\
\hline Comorbid Dysthymia (N, \% Yes) & $32(38.6)$ & $39(24.7)$ & $27(30.0)$ & 0.08 \\
\hline Comorbid ADHD (N, \% Yes) & $9(10.8)$ & $26(16.5)$ & $17(18.9)$ & 0.33 \\
\hline Comorbid Oppositional/Conduct (N, \% Yes) & $4(4.8)$ & $18(11.5)$ & $11(12.2)$ & 0.19 \\
\hline Comorbid Abuse (N, \% Yes) & $22(27.2)$ & $37(23.7)$ & $20(22.7)$ & 0.78 \\
\hline Comorbid OCD (N, \% Yes) & $1(2.4)$ & $2(2.5)$ & $3(3.3)$ & 0.91 \\
\hline Conflict Behavior - Adolescent (M, SD) & $10.2(6.2)^{\dagger}$ & $9.3(6.0)^{\dagger}$ & $7.1(6.2)^{t}$ & 0.002 \\
\hline Conflict Behavior - Parent (M, SD) & $9.0(5.9)$ & $10.1(6.3)$ & $8.9(5.2)$ & 0.23 \\
\hline
\end{tabular}

Items with different superscripts are significantly different at $\mathrm{p}<0.017$ for dichotomous outcomes and $<0.05$ with Bonferroni correction for continuous outcomes.

**

M: mean; SD: standard deviation. NSSI: Non-suicidal Self-Injury. ADHD: Attention Deficit Hyperactivity Disorder. OCD: Obsessive Compulsive Disorder.

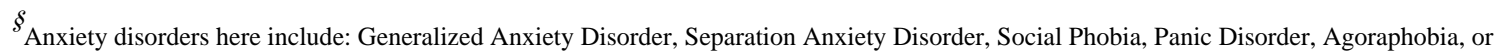
Post-Traumatic Stress Disorder. 
Table 3

Treatment-Related Differences among Classes *

\begin{tabular}{|c|c|c|c|c|c|}
\hline & & Class & & & \\
\hline & $\begin{array}{c}\mathrm{NO} \\
(\mathbf{N}=83)\end{array}$ & $\begin{array}{l}\text { SLOW } \\
(\mathbf{N}=160)\end{array}$ & $\begin{array}{c}\text { GO } \\
(\mathbf{N}=91)\end{array}$ & $\mathbf{p}$ & \\
\hline Study Med = SSRI (N, \% Yes) & $45(54.2)$ & $78(48.8)$ & $45(49.5)$ & 0.71 & \\
\hline Study Med $=\operatorname{VLX}^{* *}(\mathrm{~N}, \%$ Yes $)$ & $38(45.8)$ & $82(51.3)$ & $46(50.5)$ & & \\
\hline No CBT & $42(50.6)$ & $87(54.4)$ & $39(42.9)$ & 0.21 & \\
\hline CBT & $41(49.4)$ & $73(45.6)$ & $52(57.1)$ & & \\
\hline $\mathcal{s}_{\text {Harm Adverse Events (Suicidal Ideation) (N,\% Yes) }}$ & $10(12.0)^{\dagger}$ & $22(13.8)^{\dagger}$ & $2(2.2)^{*}$ & 0.01 & \\
\hline$\S_{\text {Harm Adverse Events (Suicide Attempts) (N, \% Yes) }}$ & $6(7.2)$ & $9(5.6)$ & $2(2.2)$ & 0.26 & \\
\hline $\mathcal{s}_{\text {Harm Adverse Events (NSSI) }}(\mathrm{N}, \%$ Yes) & $11(13.3)$ & $15(9.4)$ & $5(5.5)$ & 0.21 & \\
\hline Response at week 6 (N (\%Responder)) & $2(2.8)^{\dagger}$ & $34(24.3)^{* t}$ & $43(53.1)^{\xi}$ & $<0.001$ & \\
\hline CDRS \% change (week 0-6) (M, SD) & $20.0(25.2)^{\dagger}$ & $31.3(30.1)^{* t}$ & $56.1(28.7)^{\xi}$ & $<0.001$ & \\
\hline Remission rate at week 6 (N (\%Responder)) & $0(0.0)^{\dagger}$ & $2(1.3)^{\dagger}$ & $14(15.4)^{*}$ & $<0.001$ & \\
\hline${ }^{¥}$ Anxiolytics weeks $0-12, \mathrm{~N}$ (\% Yes) & $5(6.0)^{\dagger}$ & $7(4.4)^{\dagger}$ & $0(0.0)^{\dagger}$ & 0.04 & \\
\hline${ }^{¥}$ Mood stabilizers weeks 0-12 (N, \%Yes) & $2(2.5)$ & $8(5.3)$ & $1(1.1)$ & 0.23 & \\
\hline${ }^{¥}$ Non-SSRI/SNRI weeks 0-12, N (\% Yes) & $1(1.2)$ & $3(2.0)$ & $1(1.1)$ & $>0.99$ & \\
\hline${ }^{¥}$ Sleep meds weeks $0-12, \mathrm{~N}$ (\% Yes) & $22(26.5)$ & $28(17.5)$ & $12(13.2)$ & 0.07 & \\
\hline${ }^{¥}$ Stimulants weeks $0-12, \mathrm{~N}$ (\% Yes) & $8(9.6)$ & $29(18.1)$ & $9(9.9)$ & 0.09 & \\
\hline$\xi_{\text {Adjunctive Psychotherapy weeks } 0-12}$ & $26(31.3)^{\dagger}$ & $39(24.4)^{\dagger, t}$ & $11(12.1)^{\dagger}$ & 0.008 & \\
\hline \multicolumn{6}{|c|}{$\begin{array}{l}\text { Items with different superscripts are significantly different at } \mathrm{p}<0.017 \text { for dichotomous outcomes and }<0.05 \text { with Bonferroni correction for } \\
\text { ontinuous outcomes. }\end{array}$} \\
\hline \multicolumn{6}{|l|}{ *** VLX: Venlafaxine } \\
\hline \multicolumn{6}{|l|}{$\xi_{\text {During the first } 12 \text {-weeks }}$} \\
\hline TX refers to adjunctive treatment received. & & & & & \\
\hline
\end{tabular}

